\title{
Downregulation of immunological mediators in 2,4-dinitrofluorobenzene-induced atopic dermatitis-like skin lesions by hydrocortisone- loaded chitosan nanoparticles
}

\author{
This article was published in the following Dove Press journal: \\ International Journal of Nanomedicine \\ 5 November 2014 \\ Number of times this article has been viewed
}

\author{
Zahid Hussain' \\ Haliza Katas' \\ Mohd Cairul lqbal Mohd \\ Amin' \\ Endang Kumolosasi \\ Shariza Sahudin ${ }^{2}$ \\ 'Centre for Drug Delivery Research, \\ Faculty of Pharmacy, Universiti \\ Kebangsaan Malaysia, Kuala Lumpur, \\ Malaysia; ${ }^{2}$ Faculty of Pharmacy, \\ Universiti Teknologi MARA, Puncak \\ Alam Campus, Bandar Puncak Alam, \\ Selangor, Malaysia
}

Background: Atopic dermatitis is a chronic, noncontiguous, and exudative disorder accompanied by perivascular infiltration of immune mediators, including T-helper (Type 1 helper/Type 2 helper) cells, mast cells, and immunoglobulin E. The current study explores the immunomodulatory and histological effects of nanoparticle (NP)-based transcutaneous delivery of hydrocortisone (HC).

Methods: In this study, HC, the least potent topical glucocorticoid, was administered transcutaneously as chitosan NPs. The pharmacological and immunological effects of the NP-based $\mathrm{HC}$ delivery on the alleviation of 2,4-dinitrofluorobenzene-induced atopic dermatitis (AD)-like skin lesions were evaluated using the NC/Nga mouse model.

Results: In vivo Dino-Lite ${ }^{\circledR}$ microscopic assessment revealed that the NP-based formulation displayed a remarkable ability to reduce the severity of the pathological features of AD (dermatitis index, 3.0). The AD suppressive activity of the NP-based topical formulation was expected owing to the interruption of a series of immunopathological events, including the production of immunoglobulin E, release of histamine, and expression of prostaglandin- $\mathrm{E}_{2}$ and vascular endothelial growth factor- $\alpha$ in the sera and skin of the tested animals. Analysis of the cytokine expression in AD-like skin lesions further revealed that the NP-based formulation inhibited the pathological expression of interleukin (IL)-4, IL-5, IL-6, IL-13, IL-12p70, interferon- $\gamma$, and tumor necrosis factor- $\alpha$ in serum and skin homogenates of NC/Nga mice. Further, our histological findings indicated that the NP-based formulation inhibited fibroblast infiltration and fragmentation of elastic fibers, further supporting the clinical importance of these formulations in maintaining the integrity of elastic connective tissues.

Conclusion: The current investigation suggests that NP-mediated transcutaneous delivery of $\mathrm{HC}$ could be considered an effective therapeutic approach to manage dermatitis.

Keywords: chitosan nanocarrier, elastic fibers, glucocorticoids, topical delivery

\section{Introduction}

The use of topical glucocorticoids (TGs) is a well-established approach to relieve acute and chronic exacerbation of psoriasis and atopic dermatitis (AD) $)^{1,2}$ because of their vasoconstrictive, anti-inflammatory, immunosuppressive, and antiproliferative effects. However, long-term use of TGs is often accompanied by deleterious local and systemic side-effects, including growth retardation in infants, hypopigmentation, skin thinning, and atrophy, that limit their clinical use and exclude their application in chronic maintenance therapies., ${ }^{3,4}$ Thus, hydrocortisone (HC), a mild TG, is administered topically to minimize the unwanted effects associated with TGs. To further broaden
Correspondence: Haliza Katas Centre for Drug Delivery Research, Faculty of Pharmacy, Universiti Kebangsaan Malaysia, Kuala Lumpur Campus, Jalan Raja Muda Abdul Aziz 50300, Kuala Lumpur, Malaysia

Tel +60 39289797 I

Fax +60 26893271

Email haliz12@hotmail.com 
the therapeutic use of TGs, increase patient compliance, and minimize deleterious effects, a number of approaches have been attempted to mitigate the transcutaneous absorption of TGs.

A number of strategies have been used to reduce the adverse effects of drugs by enhancing their penetration into the skin, thus reducing the topically applied dose. Among these approaches are application of chemical enhancers, ${ }^{5}$ electroporation, ${ }^{6}$ micro-needles, ${ }^{7}$ and several vesicular delivery systems, such as colloidal carriers, ${ }^{8}$ liposomes, ${ }^{9}$ ethosomes, ${ }^{10}$ solid lipid nanoparticles (NPs), ${ }^{11}$ and nanoemulsions. ${ }^{12}$ However, the application of these formulations is limited, owing to toxicity towards stratum corneum (SC) and therapeutic impracticality. Polymeric NPs are also recognized as a noninvasive technique to facilitate the delivery of therapeutics into the $\operatorname{skin}^{13}$ and to achieve targeted delivery. ${ }^{14,15}$ Among the various biodegradable and biocompatible polymers used for the preparation of NPs, chitosan (CS) has attracted much attention, because of its mucoadhesive and transepidermal penetrative properties. ${ }^{16}$ Our group previously highlighted the usefulness of polymeric CS-NPs to achieve therapeutic levels of TGs in the epidermis and dermis, and to reduce their transcutaneous permeation. ${ }^{17}$ The success of CS-NP-based delivery is associated with their nano-range size and excellent biopharmaceutical properties, such as high entrapment efficiency (EE), controlled release rate, and protection from enzymatic degradation.

In the present investigation, the therapeutic efficacy of NP-based percutaneous delivery of $\mathrm{HC}$ was evaluated in an AD-like skin lesion model using an NC/Nga mouse model. AD typically manifests as pruritic dermatitis accompanied by perivascular infiltration of T-helper lymphocytes (Type 1 helper $\left[\mathrm{T}_{\mathrm{H} 1}\right]$ and Type 2 helper $\left[\mathrm{T}_{\mathrm{H} 2}\right]$ cytokines in chronic and acute $\mathrm{AD}$, respectively), mast cells, and immunoglobulin $\mathrm{E}$ (IgE). ${ }^{18,19}$ Both mast cells and basophils are among the key effectors in IgE-mediated allergic disorders, including AD. ${ }^{20}$ These cells are stimulated in response to active cross-linking of AD-specific IgE with high affinity cell-surface IgE-receptors. Upon activation, these cells undergo degranulation and release active inflammatory mediators, such as histamine, leukotrienes, and prostaglandin- $\mathrm{E}_{2}\left(\mathrm{PGE}_{2}\right) .{ }^{21} \mathrm{AD}$ is further aggravated by the production of vascular endothelial growth factor- $\alpha$ (VEGF- $\alpha$ ), a potent biomarker that induces hyperpermeability of blood vessels via abnormal neovascularization and endothelial cell proliferation. Additionally, VEGF- $\alpha$ acts as a chemoattractant for various inflammatory cells responsible for the persistent aggravation of erythema and edema. ${ }^{21,22}$ Finally, release of numerous $\mathrm{T}_{\mathrm{H} 1}-\mathrm{T}_{\mathrm{H} 2}$-specific inflammatory mediators, such as interleukin (IL)-4, IL-5, IL-6, IL-12p70, IL-13, interferon- $\gamma$ (IFN- $\gamma$ ), and tumor necrosis factor- $\alpha$ $(\mathrm{TNF}-\alpha)$ has been demonstrated in patients with AD. ${ }^{23,24}$

In the current study, $\mathrm{AD}$ was induced by applying 2,4dinitrofluorobenzene (DNFB) topically, and then treated with HC-loaded CS-NP formulations. The anti-inflammatory efficacy of the HC-loaded CS-NP formulations was evaluated by microscopic analysis of the AD-like skin lesions. At the end of treatment, all the experimental animals were euthanized to withdraw blood samples for immunological analysis. Moreover, the dorsal skin of the AD-induced mice was surgically excised to perform immunostaining on the infiltrated biomarkers responsible for AD. Clinical data were further evaluated by conducting histological examination to examine the histopathological features of skin including infiltrated fibroblasts, thickening/fragmentation of elastic fibers, and skin fibrosis.

\section{Materials and methods Materials}

Eight-week-old NC/Nga mice were purchased from Riken BioResource Centre (Tsukuba, Ibaraki, Japan). Isoflurane was obtained from Piramal Healthcare Limited (Kuala Lumpur, Malaysia). DNFB, acetone, CS (molecular weight, 70 $\mathrm{kDa}$; deacetylation degree, 85\%), and HC (base form) were purchased from Sigma-Aldrich Co. (St Louis, MO, USA). The halt protease inhibitor cocktail and cell lysis buffers were obtained from Thermo Fisher Scientific (Waltham, MA, USA). The chemicals used to conduct immunological studies included the IgE enzyme-linked immunosorbent assay (ELISA) kit (Abcam Chemical, Selangor, Malaysia), $\mathrm{PGE}_{2}$ ELISA kit (Cayman Chemical, Kepong, Malaysia), histamine ELISA kit (Abnova Chemicals, ATIKKA VISI CHEMICALS Sdn. Bhd., Kuala Lumpur, Malaysia), VEGF- $\alpha$ ELISA kit (Thermo Fisher Scientific), and multi-analyte profiling Procarta $^{\circledR}$ assay kit (Affymetrix, Research Instruments Sdn. Bhd., Selangor, Malaysia). All other chemicals were of analytical grade and sourced from the research laboratories at the Universiti Kebangsaan Malaysia.

\section{Preparation of nanoparticles}

HC-loaded CS-NPs were prepared according to the method described by Hussain et al. ${ }^{17} \mathrm{CS}$ solution $(25 \mathrm{~mL}, 0.2 \% \mathrm{w} / \mathrm{v}$, prepared in $1 \% \mathrm{v} / \mathrm{v}$ acetic acid, $\mathrm{pH}$ 5.0) was incubated with $\mathrm{HC}$ solution $(1 \mathrm{mg} / \mathrm{mL}$ in a 30:70 mixture of ethanol/water) with stirring for 30 minutes. HC-loaded CS-NPs were spontaneously formed by adding $10 \mathrm{~mL}$ of pentasodium tripolyphosphate solution $(0.1 \% \mathrm{w} / \mathrm{v}$, in distilled water $)$ dropwise with constant 
stirring at $700 \mathrm{rpm}$. The resulting $\mathrm{HC}$-loaded CS-NPs were harvested by ultracentrifugation $(28,000 \mathrm{rpm})$ for 30 minutes using an Optima L-100 XP Ultracentrifuge with an NV 70.1 Ti rotor (Beckman-Coulter, Brea, CA, USA). The HC-loaded CS-NPs were subsequently resuspended in distilled water and lyophilized (Scanvac CoolSafe ${ }^{\mathrm{TM}}$; Chemoscience, Bangkok, Thailand) at $-40^{\circ} \mathrm{C}$ for 24 hours.

\section{Physicochemical characterization}

The HC-loaded CS-NPs recovered after ultracentrifugation were resuspended in distilled water $(3 \mathrm{~mL})$ for measurement of the mean particle size, polydispersity index, and zeta potential using a ZS-90 Zetasizer ${ }^{\circledR}$ (Malvern Instruments, Malvern, UK). All measurements were performed in triplicate at $25^{\circ} \mathrm{C}$ with a detection angle of $90^{\circ}$. Data are reported as the mean \pm standard deviation (SD).

The EE (\%EE) and loading capacity (\%LC) of $\mathrm{HC}$ in CS-NPs was determined by using high-performance liquid chromatography (HPLC). A corresponding calibration curve was made by subjecting a range of standard $\mathrm{HC}$ solutions ( 1 to $1,000 \mu \mathrm{g} / \mathrm{mL}$ ) to HPLC analysis (HPLC system with a Waters 600 controller, in-line degasser AF, 2707 Autosampler, 2998 Photodiode Array Detector, and Waters symmetry $\mathrm{C}_{18}$ column $\left.[250 \times 4.5 \mathrm{~mm} ; 5 \mu \mathrm{m}]\right)$. The mobile phase, consisting of methanol, acetonitrile, and water at a ratio of 15:27:58 (v/v), was used for the elution of $\mathrm{HC}$ and was delivered at a flow rate of $1 \mathrm{~mL} / \mathrm{min}$ with an injection volume of $20 \mu \mathrm{L}$. The maximum wavelength used to measure $\mathrm{HC}$ was $248 \mathrm{~nm}$. \%EE and \%LC of loaded drug were calculated in accordance with Equations 1 and 2, respectively, ${ }^{25}$

$$
\begin{aligned}
& \operatorname{EE}(\%)=\left(W_{t}-W_{f} / W_{t}\right) \times 100 \\
& \operatorname{LC}(\%)=\left(W_{t}-W_{f} / W_{n}\right) \times 100
\end{aligned}
$$

where, $W_{t}$ is the average initial amount of $\mathrm{HC}$, and $W_{f}$ is the average amount of free drug in the supernatant after ultracentrifugation. $W_{n}$ is the average weight of the drug-loaded CS-NPs that was obtained after ultracentrifugation $(28,000$ $\mathrm{rpm})$ and lyophilization $\left(-40^{\circ} \mathrm{C}\right.$ for 24 hours) of the CS-NPs. In this experiment, the $W_{n}$ value for HC-loaded CS-NPs was $25 \pm 1.8 \mathrm{mg}$. All measurements were performed in triplicate and the data are reported as mean $\pm \mathrm{SD}$.

\section{Topical formulations with semisolid consistency}

To formulate the HC-loaded CS-NPs for topical delivery, two over-the-counter creams (QV- and aqueous cream) were used as vehicle bases. The vehicle bases were liquefied in a water bath (BW-20G; Lab Companion, San Diego, CA, USA) at $50^{\circ} \mathrm{C}$ to achieve adequate uniformity of contents and a homogenous dispersive system. Subsequently, 1,613 $\mathrm{mg}$ (calculated based on the \%LC) of lyophilized HC-loaded CS-NPs containing $0.5 \% \mathrm{w} / \mathrm{w} \mathrm{HC}$ was vigorously blended into either $100 \mathrm{~g}$ of QV- or aqueous-vehicle base to formulate the HC-loaded CS-NP-based formulations (QV-HC-CS-NPs and A-HC-CS-NPs, respectively). The compounded formulations were then placed in amber glass containers and stored in a cool and dry place prior to analysis.

\section{Characterization of test formulations}

The test formulations were characterized for drug contents, $\mathrm{pH}$, and the apparent viscosities.

\section{Drug content determination}

To evaluate the drug content, a standard calibration curve of HC was prepared. Various HC standards $(1-1,000 \mu \mathrm{g} / \mathrm{mL})$ were subjected to HPLC analysis. Each of the test formulations $(1 \mathrm{~g})$ were placed in a separate volumetric flask prefilled with $60 \mathrm{~mL}$ of a solvent containing methanol and acetonitrile (90:10 v/v ratio), and subsequently filled to a final volume of $100 \mathrm{~mL}$ using the same solvent. Volumetric flasks were then shaken overnight using a hot plate stirrer $\left(37^{\circ} \mathrm{C} \pm 0.5^{\circ} \mathrm{C}\right)$ for complete extraction of the drug contents from the CS-NPs' matrices. The mixtures were then passed through a $0.45-\mu \mathrm{m}$ polytetrafluoroethylene filter, and diluted tenfold using the same solvent mixture. Diluted samples were then analyzed by HPLC, and the peaks and area under the curve were subjected to regression analysis for drug quantification.

\section{$\mathrm{pH}$}

The $\mathrm{pH}$ of the test formulations was determined using a FE20FiveEasy ${ }^{\mathrm{TM}} \mathrm{pH}$ meter (Mettler Toledo, Columbus, OH, USA). The $\mathrm{pH}$ meter probe was carefully immersed into each test formulation. To obtain equilibrium, each test formulation was left undisturbed for 1 minute after thorough stirring. The probe was then washed with $10 \%$ ethanol and distilled water before subsequent experiments. Each experiment was performed in triplicate and data were reported as mean $\pm \mathrm{SD}$.

\section{Flow mechanics and apparent viscosity}

Flow mechanics and apparent viscosities of the QV-HCCS-NPs and A-HC-CS-NPs were determined using a Bohlin Gemini Rheometer and Viscometer (Aimil Ltd., Instrumentation and Technology, New Delhi, India). The rheometer was engaged with a cone and plate system $(1 \% / 40 \mathrm{~mm})$ and a fully integrated Peltier device (a forced 
gas oven with optional liquid nitrogen cooling and electrical heating facilities). The applied strain rates ranged from 0.005 to $300 \mathrm{~s}^{-1}$, with a broad torque range. Each experiment was run for 2 minutes, followed by 2 minutes at a constant strain rate of zero. All measurements were performed in triplicate at $32^{\circ} \mathrm{C}$ with accurately controlled shear rates.

\section{In vivo animal studies}

Animals

Eight-week-old NC/Nga mice were obtained after serial breeding (single-line) to reduce genomic diversity. Mice were acclimated for 1 week in individually ventilated cage assemblies with inlet air filters, and maintained in an air-conditioned environment with a 12-hour light/12-hour dark cycle at a controlled temperature $\left(22^{\circ} \mathrm{C} \pm 1^{\circ} \mathrm{C}\right)$ and humidity $(60 \% \pm 5 \%)$. Mice were provided with laboratory diet and water ad libitum. Experimental protocols for animal handling were in accordance with the National Institute of Health guidelines and approved by the Animal Ethics Committee of Universiti Kebangsaan Malaysia under the project approval code FF/2011/HALIZA/30-NOVEMBER/408-NOVEMBER2011-DECEMBER-2012.

\section{Induction of $A D$ and test groups}

Prior to inducing AD, the dorsal region of the NC/Nga mice was shaved, taking precaution to avoid any skin abrasions. $\mathrm{AD}$ induction was initiated by sensitizing anesthetized mice with $100 \mu \mathrm{L}$ of $0.15 \%$ DNFB in acetone/olive oil $(3: 1)$ on the shaved dorsal skin once on days 1 and 5. On days 9, 11, and $13,100 \mu \mathrm{L}$ of $0.2 \%$ DNFB was reapplied to the sensitized mouse dorsal skin as described previously. NC/Nga mice were then randomly divided into seven groups $(n=6)$. Mice in which AD was not induced were used as the baseline group. The second group was the negative control (NGCONT), containing mice that received repeated topical DNFB treatment without pharmacological treatment. The third and fourth groups were vehicle groups (VGR), consisting of AD-induced mice treated with vehicle creams (QV- and aqueous creams, respectively). The fifth group consisted of AD-induced mice treated with commercial DermAid 0.5\% cream, which was used as a positive control (POS-CONT). The sixth and seventh groups were AD-induced mice treated with the QV- and aqueous-based HC-loaded CS-NP formulations (QV-HC-CS-NPs and A-HC-CS-NPs, respectively).

\section{Evaluation of dermatitis severity}

\section{Dermatitis index and microscopic examination}

The anti-AD efficacy of the HC-loaded CS-NP formulations was examined by two dermatologists blinded to each group tested according to the following criteria: 1) erythema/ hemorrhage; 2) dryness/scaling; 3) edema/swelling; and 4) erosion/excoriation. Each parameter was scored as 0 (none), 1 (mild), 2 (moderate), or 3 (severe). The sum of the individual scores was then taken as the dermatitis index (ADI). An advance digital light microscope (Dinolite ${ }^{\circledR}$; Courage and Khazaka, Cologne, Germany) was also used to microscopically examine the severity of the AD-like skin lesions in each group tested.

\section{Test specimen collection and serum preparation}

Blood and skin biopsy specimens for immunological and histological examinations were collected after the mice were euthanized by exposure to isoflurane. The collected blood samples were individually placed into Eppendorf tubes and allowed to incubate for 30 minutes at $25^{\circ} \mathrm{C} \pm 1^{\circ} \mathrm{C}$ to accelerate clot formation. All samples were then incubated at $4^{\circ} \mathrm{C}$ overnight to contract the formed blood clots prior to centrifugation $(2,000 \mathrm{~g})$ at $4{ }^{\circ} \mathrm{C}$ for 15 minutes. Subsequently, the serum (pale yellow liquid) was carefully withdrawn and stored at $-80^{\circ} \mathrm{C}$ until further analysis.

\section{Skin specimen histology and immunostaining}

Dorsal skin samples were surgically excised and stored in $10 \%$ buffered formalin for histological analysis. Samples were wrapped in aluminum foil and stored at $-80^{\circ} \mathrm{C}$ for subsequent immunostaining.

All endogenous and exogenous AD mediators that infiltrated into the skin lesion sites were extracted as skin homogenates. To prepare the skin homogenates, $1 \mathrm{~g}$ of excised skin was cut into small grain-sized sections and placed into $2 \mathrm{~mL}$ tubes prefilled with three grinding iron beads $(2.8 \mathrm{~mm}$ in diameter). Ice-cold lysis buffer $(300 \mu \mathrm{L}$; $25 \mathrm{mM}$ bicine and $150 \mathrm{mM}$ sodium chloride, $\mathrm{pH}$ 7.6) was added to each tube with the halt protease inhibitor cocktail. The extraction tubes were then homogenized three times by using a tissue homogenizer (Bioprep-24 homogenizer) with a preset speed $(6 \mathrm{~m} / \mathrm{s})$ for 40 seconds and a resting period of 20 seconds. Extraction tubes were then centrifuged (13,000 rpm) for 2 minutes, and the tissue homogenate (top layer) was carefully removed and stored at $-80^{\circ} \mathrm{C}$ for further analysis.

\section{In vivo immunomodulatory efficacy}

To determine the mechanisms involved in the development of AD-like skin lesions, IgE, histamine, PGE 2 , VEGF- $\alpha$, and $A D$-associated $\mathrm{T}_{\mathrm{H} 1}$ (IL-12p70, IFN- $\gamma$ ), $\mathrm{T}_{\mathrm{H} 2}$ (IL-4, IL-5, IL-13), and proinflammatory cytokines (IL-6, TNF- $\alpha$ ) were 
examined in the serum and skin homogenates from all experimental mice. Data are expressed as mean $\pm \mathrm{SD}$.

\section{Measurement of relative expression of lgE,} histamine, PGE $E_{2}$, and VEGF- $\alpha$

The expression levels of IgE were measured by using specific sandwiched-type ELISAs according to the respective manufacturers' instructions.

\section{Procarta ${ }^{\circledR}$ immunoassay}

Expression of the major exogenous/endogenous ADassociated cytokines (IL-4, IL-5, IL-6, IL-12p70, IL-13, IFN- $\gamma$, and TNF- $\alpha$ ) in serum and skin homogenates was determined using the Procarta ${ }^{\circledR}$ immunoassay. The Procarta $^{\circledR}$ immunoassay is a high-throughput multiplex immunoassay with high reproducibility that enables simultaneous quantification of multiple target proteins. Furthermore, it is a highly sensitive assay $(>5.0 \mathrm{pg} / \mathrm{mL})$ and can effectively multiplex several inflammatory mediators in a sample unit.

\section{Histological observation of skin lesion for elastic fibers}

Previously stored skin specimens $(5 \mathrm{~mm})$ were embedded in paraffin wax for serial sectioning $(5 \mu \mathrm{m})$ using a microtome. Prepared skin sections were then passed through a serial rehydration and dehydration process using various concentrations of alcohol $(95 \%, 80 \%, 70 \%$, and $50 \% \mathrm{v} / \mathrm{v})$.
Slides were then stained with Verhoeff-Van Gieson stain. Pathological changes in elastic tissue fibers were viewed under a light microscope equipped with image analysis software (VideoTesT-Master Morphology; VideoTesT, St Petersburg, Russia).

\section{Statistical analysis}

Data are presented as mean $\pm \mathrm{SD}$, and were analyzed using either the paired Student's $t$-test or analysis of variance (ANOVA) followed by Tukey's post hoc analysis. For content determination and $\mathrm{pH}$ values, differences among the groups were considered statistically significant when $P<0.05$. For immunological testing, $P<0.005$ indicated a significant difference between NP-based formulations and NG-CONT/VGR.

\section{Results and discussion \\ Physicochemical characteristics of nanoparticles}

HC-loaded CS-NPs had a mean particle size of $214 \pm 12 \mathrm{~nm}$ and a narrow particle size distribution (polydispersity index $=0.321 \pm 0.029$ ). The average surface charge measured for the HC-loaded CS-NPs was $+40 \pm 4 \mathrm{mV}$, with a zeta deviation of approximately $3.54 \mathrm{mV}$. The $\% \mathrm{EE}$ and $\% \mathrm{LC}$ of $\mathrm{HC}$ entrapped in CS-NPs was $79 \% \pm 7 \%$ and $31 \% \pm 2 \%$, respectively. The particle size and zeta potential distribution histograms as well as the morphology of the HC-loaded CSNPs are presented in Figure 1A-C, respectively.

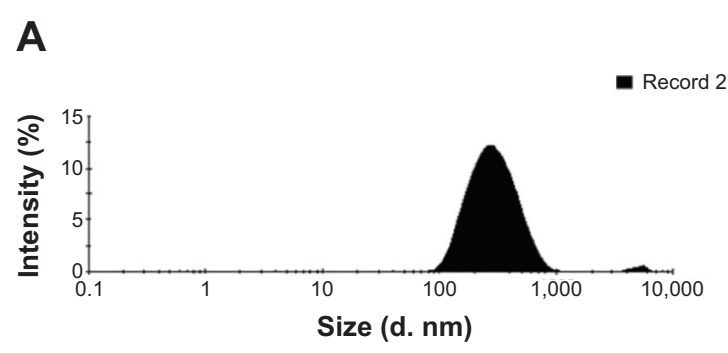

B

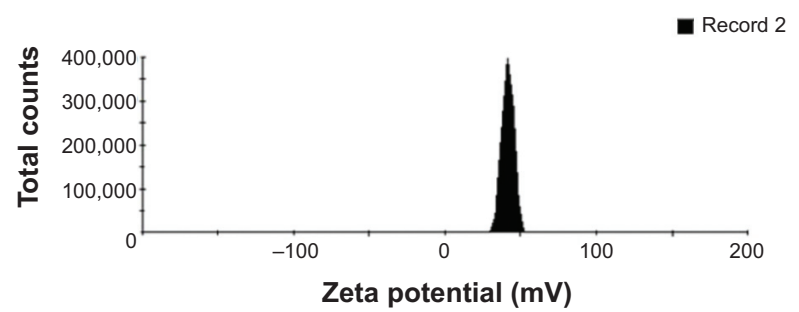

C

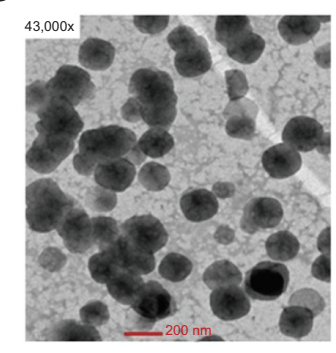

Figure I Physiochemical characteristics of HC-loaded CS-NPs.

Notes: (A) Particle size distribution histogram. (B) Zeta potential distribution histogram. (C) Morphology of HC-loaded CS-NPs using transmission electron microscope. Abbreviations: CS-NPs, chitosan nanoparticles; HC, hydrocortisone. 


\section{Physicochemical characteristics of NP- based formulations \\ Drug content}

The drug content was analyzed to ensure homogeneous dispersion of HC-loaded CS-NPs in the QV- and aqueous formulations. The absolute recovery of $\mathrm{HC}$ from the $\mathrm{QV}$ - and aqueous-based HC-loaded CS-NP formulations was $\sim 77.5 \%$ and $\sim 73.2 \%$, respectively (Table 1 ). The recovery of $\mathrm{HC}$ was more efficient from the QV-based formulation than the aqueous-based formulation. The differences in $\mathrm{HC}$ recovered could be due to solvent-solute interactions between extracting solvent system and the creams that might affect dissolution and drug release. Furthermore, the absolute recovery of $\mathrm{HC}$ from the NP-based formulations was significantly lower than the POS-CONT formulation (DermAid 0.5\%, $P<0.05$, paired $t$-test), as shown in Table 1 . This could be due to incomplete extraction of the drug, because some $\mathrm{HC}$ molecules may remain entrapped in the NP matrices. The presence of the CS polymeric network may also prevent direct release of entrapped $\mathrm{HC}$ molecules into the extracting media.

\section{$\mathrm{pH}$, apparent viscosity, and flow mechanics}

As shown in Table 1, the $\mathrm{pH}$ of the QV-based HC-loaded CS-NPs $(5.42 \pm 0.24)$ was slightly higher than that of the aqueous counterpart (5.19 \pm 0.08$)$. Both values were significantly lower than the POS-CONT formulation (6.23 \pm 0.07$)$. The presence of the intact polymeric form of CS ( $\mathrm{p} K_{\mathrm{a}}$, 6.5) or its acidified form may account for the lower $\mathrm{pH}$ in the NP-based formulations. In contrast, the QV-based HC-loaded CS-NPs had a higher apparent viscosity than the aqueous-based HC-loaded CS-NPs (Table 1). This could be owing to the thickening effect of paraffinum subliquidum $(85 \% \mathrm{w} / \mathrm{w})$ in the QV-based formulation. These values were higher than the POS-CONT formulation values $(0.3237 \pm 0.012 \mathrm{~Pa} / \mathrm{s})$ because the lyophilized HC-loaded CS-NPs tend to reduce shear thinning effects in the contained formulation. ${ }^{26}$

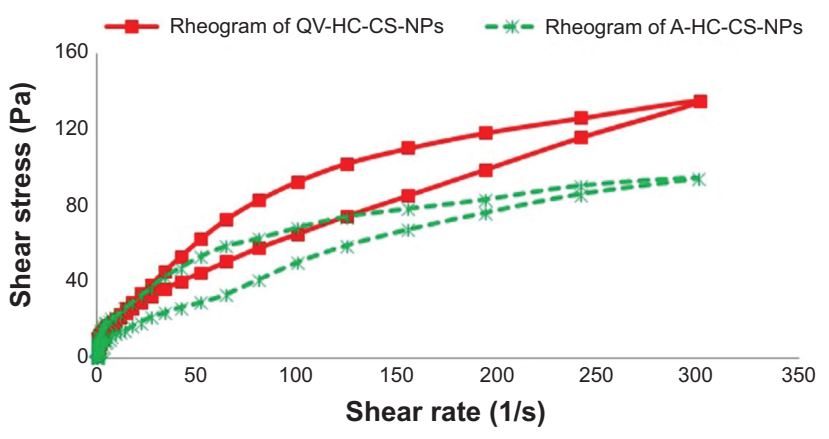

Figure 2 Flow mechanics of QV- and aqueous-based formulations in the form of rheograms of QV- and aqueous NP-based formulations.

Note: Results represent the non-Newtonian mechanics of both formulations.

Abbreviations: A-HC-CS-NPs, aqueous-based HC-loaded CS-NP formulation; CS, chitosan; HC, hydrocortisone; NP, nanoparticle; QV-, QV-cream; QV-HC-CSNPs, QV-based HC-loaded CS-NP formulation.

Flow mechanics is an important parameter to determine the flow characteristics and colloidal stability of formulations. ${ }^{27}$ The rheograms of QV-based and aqueous HC-loaded CS-NP formulations are shown in Figure 2. The rate and extent of shear stress on the QV- and aqueous-based HCloaded CS-NP formulations were proportional to the applied strain rates. These results are in accordance with those of a previous study. ${ }^{26}$ The rate and extent of shear stress in any formulation that is proportionally correlated with applied strain rate will follow non-Newtonian mechanics. Furthermore, the QV-based HC-loaded CS-NPs exhibited greater thixotropic behavior than the aqueous-based HC-loaded CS-NPs. This could be due to the thickening effect of paraffinum subliquidum $(85 \% \mathrm{w} / \mathrm{w})$ in the $\mathrm{QV}$-cream. Increases in shear stress due to enhanced strain rates could be caused by structural breakdown of particulate matter that was held together by weak bonds. ${ }^{26}$ This could lead to the formation of aggregates and reduce apparent viscosity.

\section{In vivo anti-inflammatory efficacy}

Microscopic examination

The atopic (NG-CONT) group showed the most severe dermatitis (ADI =11.0). Various pathological features, including severe erythema, hemorrhage, edema, release of

Table I Drug content, $\mathrm{pH}$, and apparent viscosity of tested formulations

\begin{tabular}{lllllll}
\hline Tested formulations & $\begin{array}{l}\text { Sample } \\
\text { weight } \\
(\mathbf{g})\end{array}$ & $\begin{array}{l}\text { Theoretical drug } \\
\text { weight entrapped } \\
\mathbf{( g )}\end{array}$ & $\begin{array}{l}\text { Actual drug weight } \\
\text { recovered } \\
\mathbf{H C}\end{array}$ & $\begin{array}{l}\text { Absolute recovery } \\
\mathbf{H C}\end{array}$ & $\begin{array}{l}\text { pH } \\
\mathbf{H C}\end{array}$ & $\begin{array}{l}\text { Apparent viscosities } \\
(\mathbf{P a} / \mathbf{s})\end{array}$ \\
\hline QV-HC-CS-NPs & 1.094 & 0.547 & 0.424 & 77.5 & $5.42 \pm 0.24$ & $0.415 \pm 0.034$ \\
A-HC-CS-NPs & 1.127 & 0.564 & 0.413 & 73.2 & $5.19 \pm 0.08$ & $0.347 \pm 0.018$ \\
POS-CONT & 1.087 & 0.543 & 0.487 & 89.6 & $6.23 \pm 0.07$ & $0.324 \pm 0.012$ \\
\hline
\end{tabular}

Note: Results are presented as mean value \pm standard deviation $(n=3)$.

Abbreviations: A, aqueous-based; HC, hydrocortisone; CS-NPs, chitosan nanoparticles; POS-CONT, positive control; QV-, QV-cream. 

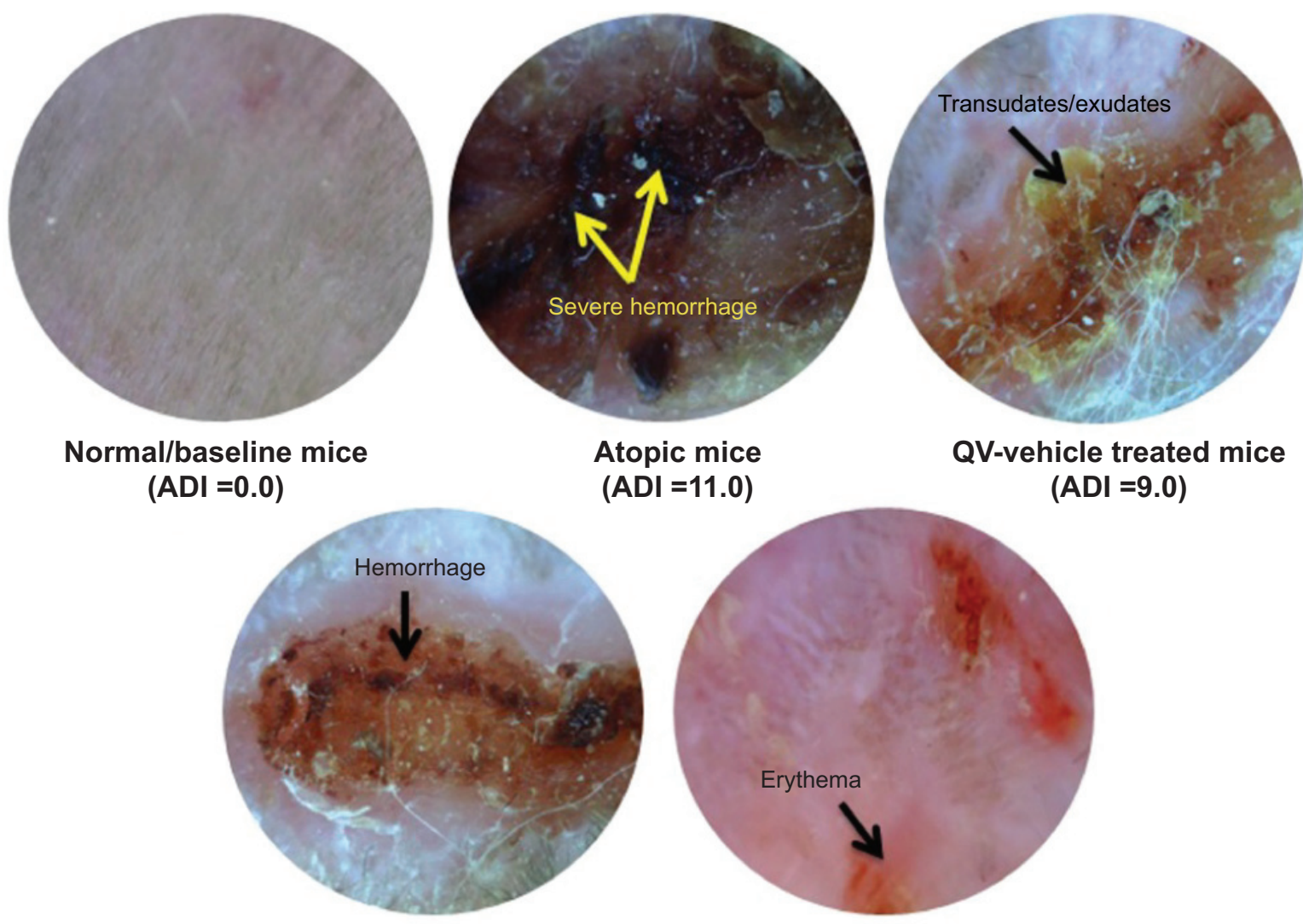

\section{Aqueous-vehicle treated mice}

(ADI =9.5)

\section{Positive control mice}

$(A D I=6.0)$
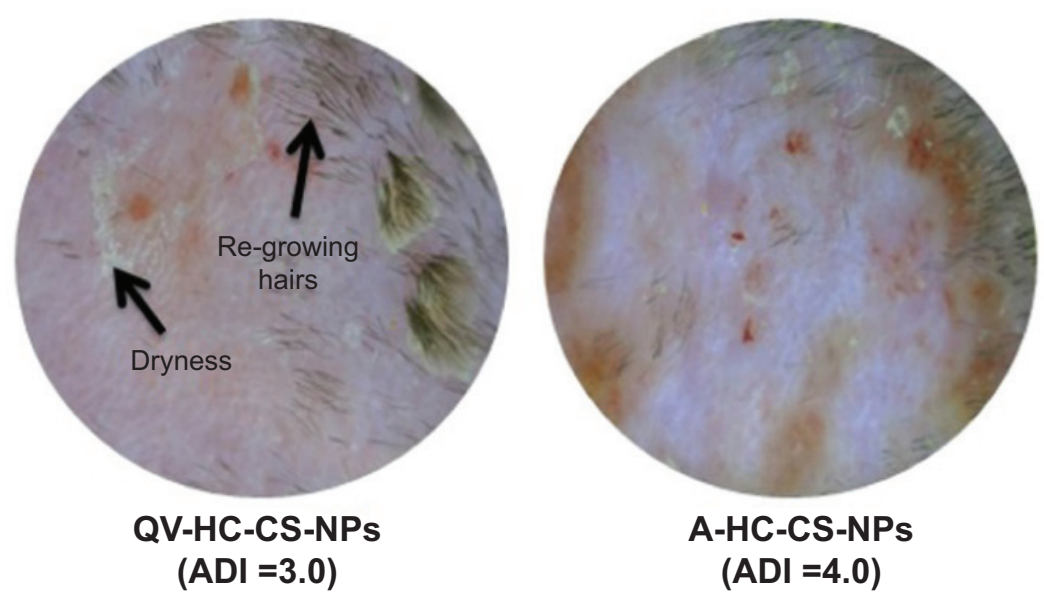

Figure 3 Clinical effectiveness of NP-based formulations compared to other groups tested in terms of digital light microscope (Dino-Lite ${ }^{\circledR}$ ) images of treated and untreated $\mathrm{AD}$-induced $\mathrm{NC} / \mathrm{Nga}$ mice.

Note: Microscopic images represent the severity of AD symptoms at the end of treatment in terms of ADI.

Abbreviations: A, aqueous-based; AD, atopic dermatitis; ADI, AD index/scores; CS, chitosan; HC, hydrocortisone; NPs, nanoparticles; QV-, QV-cream.

exudates/transudates, superficial erosion, deep excoriation, intense itching, and dry skin, were observed in the atopic group (Figure 3). The signs of AD-like skin lesions in the NGCONT group were likely the result of severe disruption in the $\mathrm{SC}$, due to intense scratching in response to severe itching. This scratching can initiate various underlying inflammatory cascades, causing the skin to become eroded and excoriated.
This would also further aggravate erythema and hemorrhage. Moreover, the AD-like skin lesions in the NG-CONT group were associated with transudates/exudates produced from the eroded area, which was also observed in the VGR, although the exudates/transudates, hemorrhage, and erosion/excoriation were reduced. In contrast, the $\mathrm{AD}$-induced mice treated with commercial DermAid 0.5\% formulation (POS-CONT) 
displayed improved $\mathrm{AD}$ symptoms $(\mathrm{ADI}=6.0)$ as compared to the NG-CONT mice. Further, the ADI of QV-HC-CS-NPs and A-HC-CS-NPs were significantly lower compared to other groups tested. Even though erythematic areas were observed in the photomicrographs of the mice treated with the NP-based formulations, they were less severe than those observed in other experimental groups. Moreover, restoration of skin integrity could be seen, because hair started to grow on the dorsal body region of the mice. These data also indicated that the QV-based NP-formulation was more effective (ADI =3.0) in treating dermatitis compared to the aqueousbased formulation (ADI $=4.0$ ). These findings suggest that the NP-based formulations were effective in maintaining skin integrity during dermatitis and treatment, with minimal symptoms of dryness and erythema.

\section{In vivo immunomodulatory efficacy $\lg \mathrm{E}$}

An important feature of $\mathrm{AD}$ is the pathological secretion of $\mathrm{IgE}$ in response to active or passive degranulation of mast cells and basophils. As shown in Figure 4A and C, the untreated atopic mice expressed the highest amount of $\operatorname{IgE}(P<0.005$, one-way ANOVA) in serum $(1,048 \pm 72 \mathrm{ng} / \mathrm{mL})$ and skin homogenates $(805 \pm 64 \mathrm{ng} / \mathrm{mL})$. These results were in accordance with those of previously published reports. ${ }^{28,29}$ The high level of IgE measured in the atopic mice was associated with the activation of underlying inflammatory cascades in response to repetitive applications of DNFB. As a result, class switching of B-lymphocytes provokes higher expression of local and systemic IgE that leads to severe dermatitis in the atopic group. The severity of the AD-like skin lesions is associated with the class switching of B-lymphocytes, which produces the IgE detected in the serum and skin homogenates. Similarly, both vehicle-treated mice groups exhibited a high level of IgE in both samples. In contrast, DermAid $0.5 \%$ cream suppressed pathological expression of $\mathrm{IgE}$ to $533 \pm 38 \mathrm{ng} / \mathrm{mL}$ and $571 \pm 74 \mathrm{ng} / \mathrm{mL}$ in the serum and skin homogenates, respectively. Further, the QV- and A-based HC-loaded CS-NP formulations caused a remarkable decrease in $\operatorname{IgE}$ expression $(P<0.005$, one-way ANOVA). The IgE levels in the QV-HC-CS-NP group was $\sim 4.5$-times lower than the atopic and VGR, and 1.8-times lower than the POS-CONT group. This was likely due to synergistic action between the $\mathrm{CS}$ and $\mathrm{HC}$, which mitigates the progression of the underlying adaptive immune response. Furthermore, the
A

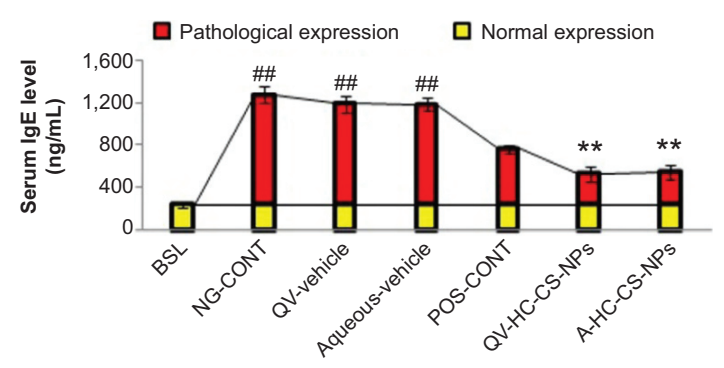

B

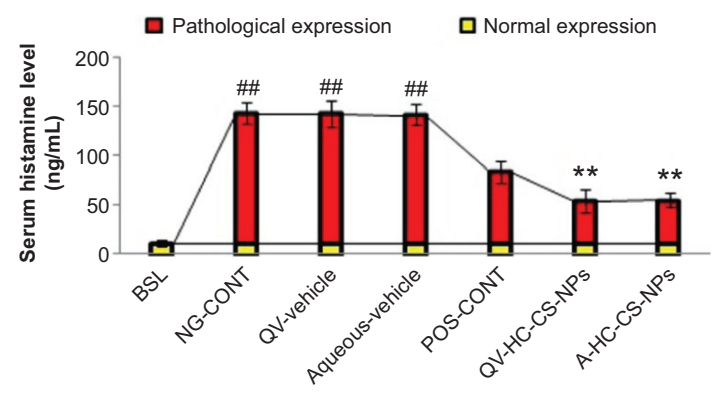

C

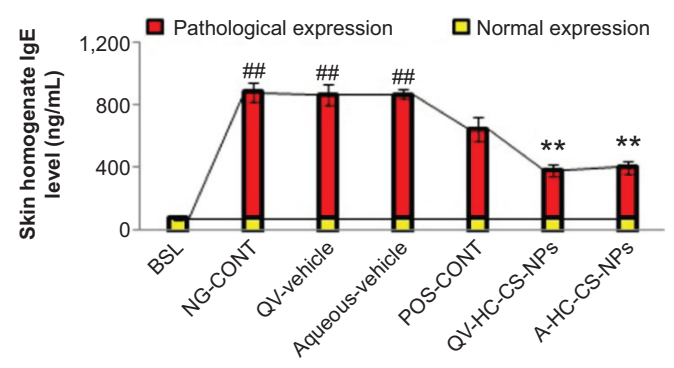

D

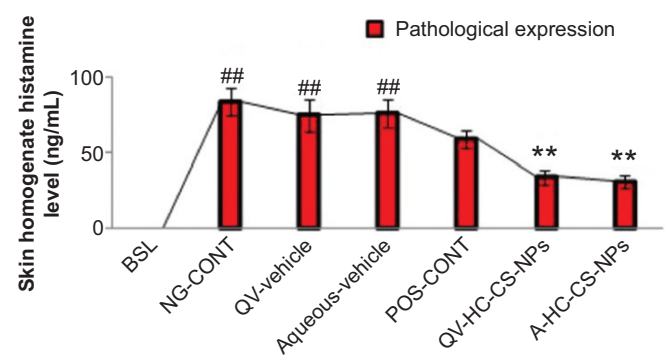

Figure 4 Immunomodulatory efficacy of NPs-based formulations.

Notes: Effect of HC-loaded CS-NP-based formulations on the pathological expression of lgE and histamine in serum (A and $\mathbf{B}$ ) and skin tissue homogenates (C and $\mathbf{D}$ ) of $\mathrm{AD}$-induced $\mathrm{NC/Nga}$ mice compared to other groups tested. The yellow part of the bars represents normal expression, and the red part represents pathological expression of $\operatorname{lgE}$ and histamine. Data are presented as mean \pm standard deviation of triplicate experiments. ${ }^{\# P}<0.005$ baseline versus atopic mice/vehicle groups; ${ }^{* *} P<0.005$ NP-based formulations versus atopic/vehicle groups.

Abbreviations: A, aqueous-based; AD, atopic dermatitis; BSL, baseline; CS, chitosan; HC, hydrocortisone; IgE, immunoglobulin-E; NG-CONT, negative control; NP, nanoparticle; POS-CONT, positive control; QV-, QV-cream. 
decrease in $\operatorname{IgE}$ expression was more prominent in the skin, which is expected due to the target-specific local effects of HC-loaded CS-NP-based formulations.

\section{Histamine}

Application of DNFB in atopic mice resulted in increased release of histamine ( $P<0.005$, one-way ANOVA) in serum $(132 \pm 11 \mathrm{ng} / \mathrm{mL})$ and the skin $(84 \pm 9 \mathrm{ng} / \mathrm{mL})$. These levels were significantly higher than those in the baseline group (Figure 4B and D). The baseline concentration of histamine in serum was $11 \pm 3 \mathrm{ng} / \mathrm{mL}$, and undetectable $(<5.0 \mathrm{pg} / \mathrm{mL})$ in the skin homogenate. High levels of histamine are the result of mast cell and basophil degranulation, which occurs following the cross-linking of $\mathrm{IgE}$ with the high-affinity histamine receptors. This induces a release of histamine at the sites of systemic and local inflammation. This condition enhances the permeability of blood vessels that facilitate the infiltration of guard cells into the dermis. The affected mice therefore experience severe itching and rashes, and have thicker skin. ${ }^{30}$ Clinical outcomes, such as the enhanced permeability and infiltration of mast cells and basophils observed in the NGCONT mice, would also aggravate erythema and hemorrhage, and thus worsen the dermatitis index (as observed in Dino-Lite ${ }^{\circledR}$ photomicrographs). The obtained data also showed that VGRs could not reduce the histamine levels in serum and the skin. Furthermore, high histamine concentrations were observed in vehicle-treated mice. In contrast, the POS-CONT mice showed a considerable reduction in histamine levels in serum $(73 \pm 11 \mathrm{ng} / \mathrm{mL})$ and skin homogenates $(59 \pm 6 \mathrm{ng} / \mathrm{mL})$. Interestingly, HC-loaded CS-NP-based formulations, particularly QV-HC-CS-NPs, significantly $(P<0.005$, one-way ANOVA) reduced histamine levels in serum and skin homogenates.

\section{$\mathrm{PGE}_{2}$}

The NG-CONT group expressed the highest $\mathrm{PGE}_{2}$ levels $(P<0.005$, one-way ANOVA) in serum $(216 \pm 19 \mathrm{ng} / \mathrm{mL})$ and skin $(67 \pm 17 \mathrm{ng} / \mathrm{mL})$, as shown in Figure 5A and C. High levels of $\mathrm{PGE}_{2}$ contribute to underlying allergic episodes, itching, and rashes at the site of AD. Vigorous scratching can damage the $\mathrm{SC}$ and other epidermal layers, thereby activating the arachidonic acid pathway via phospholipase- $\mathrm{A}_{2}$, and producing other prostaglandins and leukotrienes that further worsen the skin lesions. The expression of $\mathrm{PGE}_{2}$ in the VGR was similar to the NG-CONT group. In contrast, the POS-CONT group showed considerable suppression of $\mathrm{PGE}_{2}$ levels, which was
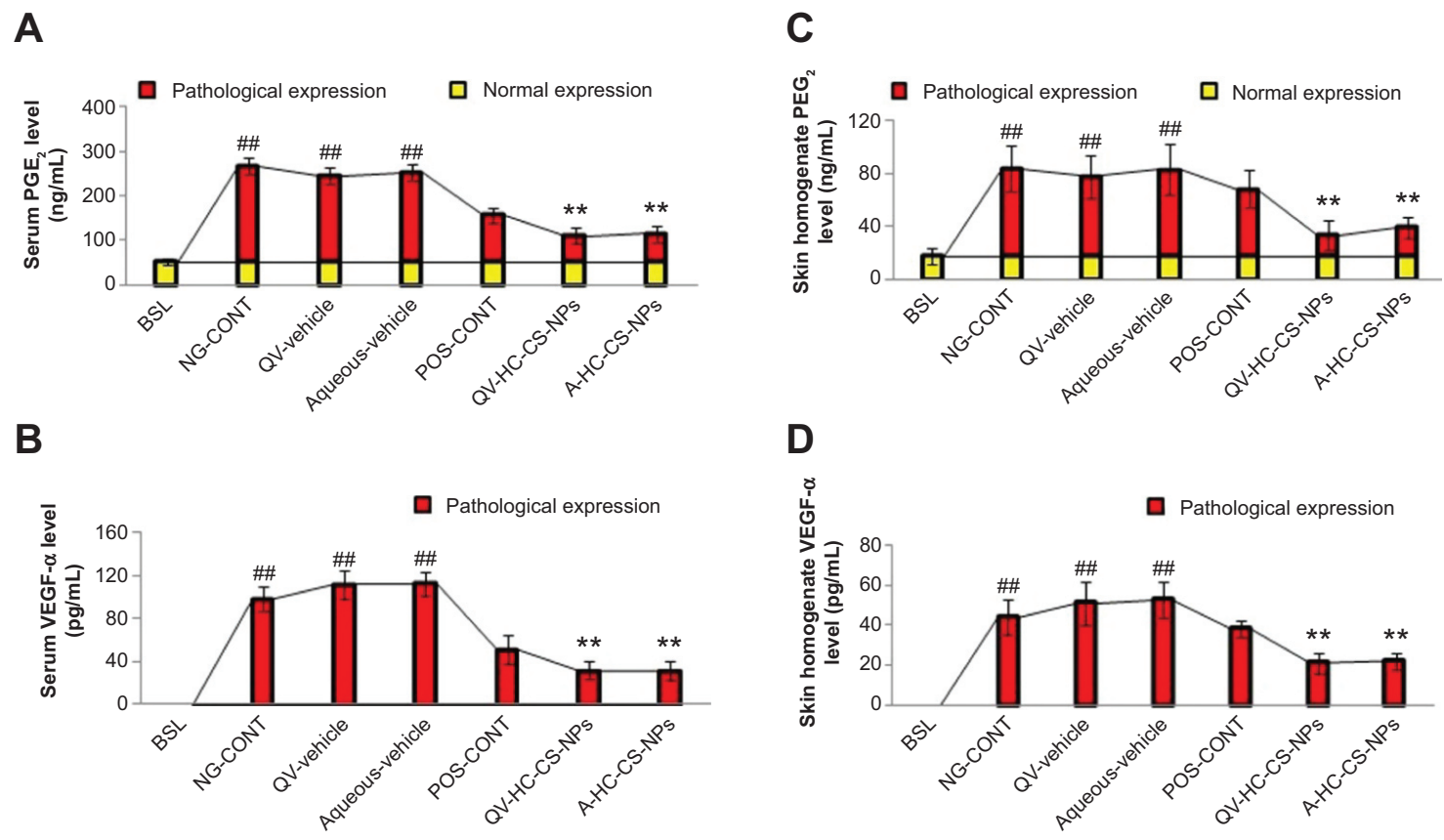

Figure 5 Immunomodulatory efficacy of NPs-based formulations.

Notes: Effect of HC-loaded CS-NP-based formulations on the expression of PGE ${ }_{2}$ and VEGF- $\alpha$ in serum (A and $\left.\mathbf{B}\right)$ and skin tissue homogenates (C and $\left.\mathbf{D}\right)$ of AD-induced $\mathrm{NC/Nga}$ mice groups compared to other groups tested. The yellow part of the bars represent normal expression, and the red part represents pathological expression of $\mathrm{PGE}_{2}$ and VEGF- $\alpha$. The concentration of VEGF- $\alpha$ was below detection limit $(<5 \mathrm{pg} / \mathrm{mL})$ in serum and skin tissue homogenates in baseline mice. Data are presented as mean \pm standard deviation of triplicate experiments. ${ }^{\# P}<0.005$ baseline versus atopic mice/vehicle groups; $* * P<0.005$ NP-based formulations versus atopic/vehicle groups. Abbreviations: A, aqueous-based; AD, atopic dermatitis; BSL, baseline; CS, chitosan; HC, hydrocortisone; NG-CONT, negative control; NP, nanoparticle; PGE 2 , prostaglandin E2; POS-CONT, positive control; QV-, QV-cream; VEGF- $\alpha$ is vascular endothelial growth factor- $\alpha$. 
more prominent in serum (Figure $5 \mathrm{~A}$ and $\mathrm{C}$ ). This finding could be associated with the inhibitory effect of $\mathrm{HC}$ on phospholipase- $\mathrm{A}_{2}$, which in turn blocks local and systemic prostaglandin synthesis. ${ }^{31}$ Further, both QV-HC-CS-NPs and A-HC-CS-NPs efficiently reduced the systemic and local expression of $\mathrm{PGE}_{2}$ (Figure $5 \mathrm{~A}$ and $\mathrm{C}$ ). The remarkable inhibition of $\mathrm{PGE}_{2}$ by the NP-based formulations, specifically in the skin, is attributed to their ability to target $\mathrm{HC}$ to the epidermis and dermis.

\section{Vascular permeability factor}

VEGF- $\alpha$ is a vascular permeability factor that regulates the pathogenesis of AD-like skin lesions. Our results demonstrated that VEGF- $\alpha$ expression is significantly upregulated in the serum and skin of the NG-CONT and VGR (Figure 5B and $\mathrm{D}, P<0.005$, one-way ANOVA). In contrast, VEGF- $\alpha$ was below the detectable limit $(<5.0 \mathrm{pg} / \mathrm{mL})$ in the serum and skin of the baseline group. Expression of VEGF- $\alpha$ may therefore represent a pathological indicator of dermatitis. High levels of VEGF- $\alpha$ may initiate vasculogenesis and angiogenesis. Moreover, it enhances the permeability of blood vessels and infiltration of immune cells into the skin. Severe dermatitis, such as that characterized by the ADlike skin lesions observed in the atopic group and VGR, may be the result of VEGF- $\alpha$ expression, because it acts as a chemoattractant for various inflammatory cells that aggravate the underlying inflammatory reactions. Similar to histamine, topical application of the NP-based formulations significantly reduced VEGF- $\alpha$ levels in serum and skin. Thus, the retention of therapeutic concentrations of targeted drug in the epidermis and dermis by NP-based formulations may reduce the underlying $\mathrm{AD}$ cascades and block synthesis of VEGF- $\alpha$.

\section{$\mathrm{T}_{\mathrm{HI}}$-producing cytokines}

We further evaluated key immunological cytokines that contribute to the pathological severity of dermatitis, including IL-12p70 and IFN- $\gamma$. As shown in Figure 6A and C, the untreated atopic mice expressed higher concentrations of IL-12p70 in serum $(62 \pm 11 \mathrm{pg} / \mathrm{mL})$ and skin $(27 \pm 9 \mathrm{pg} / \mathrm{mL})$ compared with the baseline group $(P<0.005$, one-way ANOVA). Similarly, IFN- $\gamma$ levels were higher in the serum and skin homogenates of untreated atopic mice (Figure 6B and D). These findings were in agreement with those of a previously published study. ${ }^{18}$ According to this report, IL-12p70 is overexpressed by infiltrated inflammatory cells, such as natural killer cells, macrophages, and eosinophils,
A

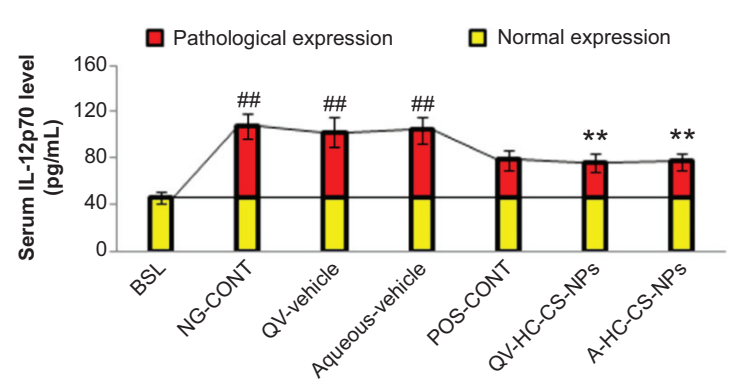

B

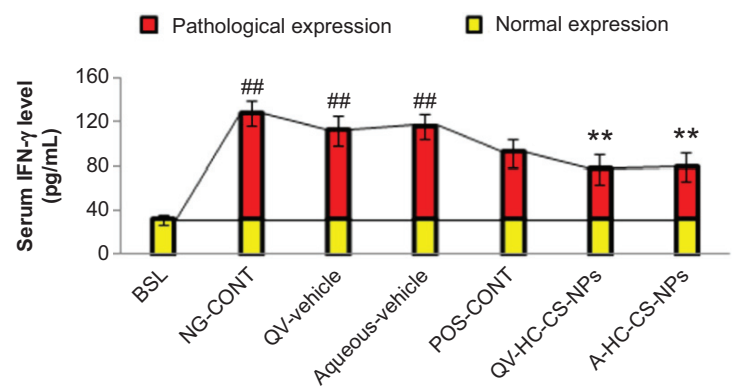

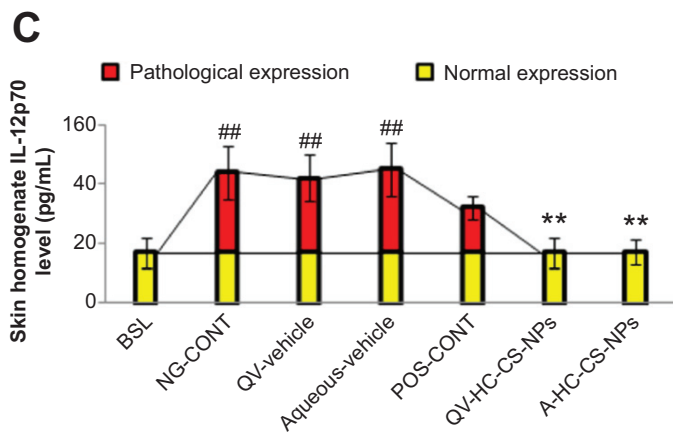

D

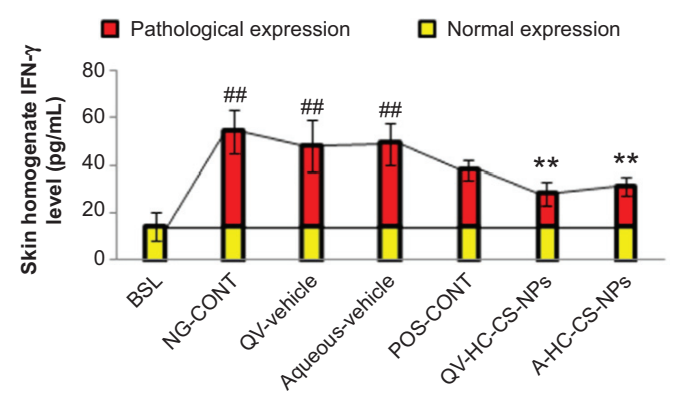

Figure 6 Immunomodulatory efficacy of NPs-based formulations.

Notes: Effect of HC-loaded CS-NP-based formulations on the concentration of IL-I2p70 and IFN- $\gamma$ in serum (A and B) and skin tissue homogenates (C and $\mathbf{D})$ of $A D$-induced $\mathrm{NC/Nga}$ mice compared to other groups treated. The yellow part of the bars represent normal expression and the red part represents pathological expression of IL-I 2 p70 and IFN- $\gamma$. Data are presented as mean \pm standard deviation of triplicate experiments. ${ }^{\# P}<0.005$ baseline versus atopic mice/vehicle groups; $* * P<0.005$ NP-based formulations versus atopic/vehicle groups.

Abbreviations: A, aqueous-based; AD, atopic dermatitis; BSL, baseline; CS, chitosan; HC, hydrocortisone; IFN- $\gamma$, interferon- $\gamma$; IL-I2p70, interleukin-I2p70; NG-CONT, negative control; NP, nanoparticle; POS-CONT, positive control; QV-, QV-cream. 
that migrate from systemic circulation into the dermis. Overexpression of IL-12p70 mediates sequential activation of T-helper 0 to $\mathrm{T}_{\mathrm{H} 1}$-type lymphocytes via a positive feedback mechanism. In addition, IL-12p70 stimulates signal transduction molecules to induce the overproduction of other inflammatory cytokines, including IFN- $\gamma$, further aggravating the underlying $\mathrm{AD}$ signaling cascades. The pleiotropic nature of IFN- $\gamma$ may further worsen dermatitis by inducing the proliferation and differentiation of infiltrating macrophages via macrophage-stimulating factors.

As shown in Figure 6, a slight reduction in IL-12p70 and IFN- $\gamma$ in serum and skin was observed in the VGR. However, DermAid 0.5\% masked the pathological expression of $\mathrm{T}_{\mathrm{H} 1}$-specific cytokines in both samples. This effect was expected, because $\mathrm{HC}$ diminished the infiltration of inflammatory cells that produce IL12p70 and IFN- $\gamma$. Further, the NP-based formulations significantly suppressed the expression of both $\mathrm{T}_{\mathrm{H} 1}$-specific cytokines $(P<0.005$, one-way ANOVA). This effect was more pronounced in the skin samples, due to targeting delivery of HC by the CS-NPs as previously discussed. Moreover, the reduction in IFN- $\gamma$ expression may also be associated with the immunosuppressive effects of $\mathrm{HC}$, through the inhibition of inflammatory cell chemotaxis and infiltration at the site of inflammation.

\section{$\mathrm{T}_{\mathrm{H} 2}$-specific cytokines}

The atopic group also displayed significantly elevated levels of IL-4, IL-5, and IL-13 in serum and skin homogenates compared to the baseline group (Figure 7). The baseline concentration of these mediators was below the detection

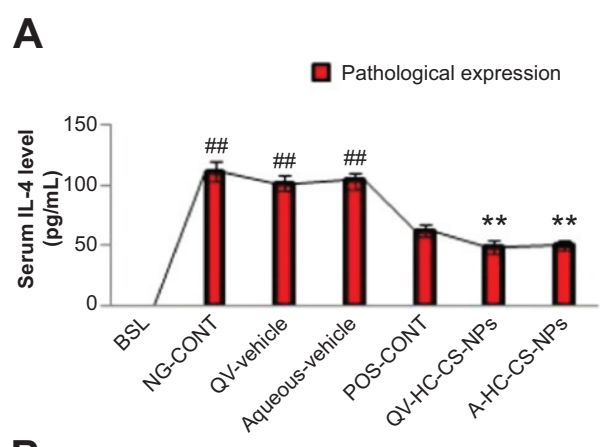

B
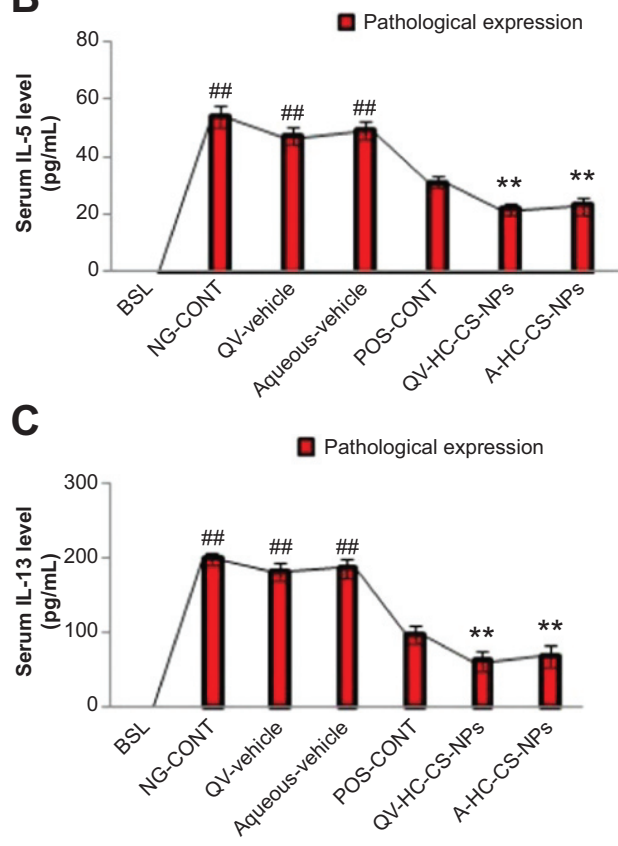

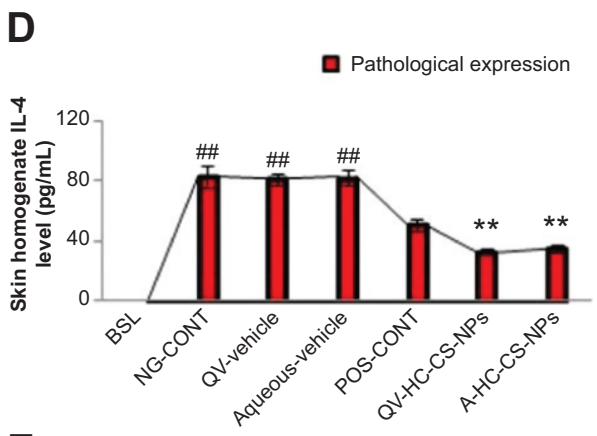

E
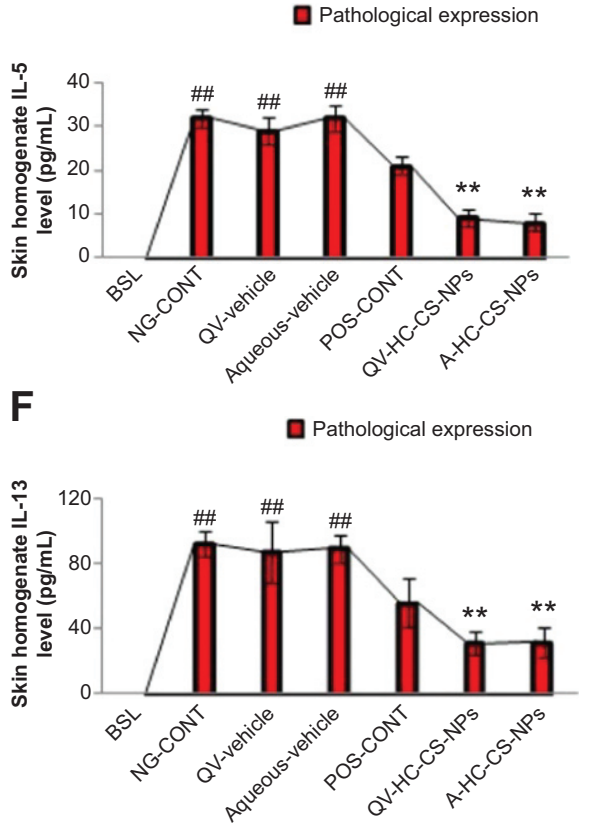

Figure 7 Immunomodulatory efficacy of NPs-based formulations.

Notes: Effect of HC-loaded CS-NP-based formulations on the expression of IL-4, IL-5, and IL-I3 in serum (A, B, and C) and skin tissue homogenates (D, E, and F) of ADinduced NC/Nga mice compared to other groups treated. Results highlight that these mediators were not detected in serum and skin tissues of baseline mice. The red parts of the bars represent the pathological expression of these $A D$-associated mediators. Data are presented as mean \pm standard deviation of triplicate experiments. ${ }^{\#} P<0.005$ baseline versus atopic mice/vehicle groups; $* * P<0.005$ NP-based formulations versus atopic/vehicle groups.

Abbreviations: A, aqueous-based; AD, atopic dermatitis; BSL, baseline; CS, chitosan; HC, hydrocortisone; IL, interleukin; NG-CONT, negative control; NP, nanoparticle; POS-CONT, positive control; QV-, QV-cream. 
$\operatorname{limit}(<5.0 \mathrm{pg} / \mathrm{mL})$. This finding suggests that the severity of AD-like skin lesions could also be associated with elevated concentrations of $\mathrm{T}_{\mathrm{H} 2}$-specific cytokines. $\mathrm{T}_{\mathrm{H} 2}$ cytokines induce differentiation of Type 0 helper cells to $\mathrm{T}_{\mathrm{H} 2}$ lymphocytes in an autoregulatory fashion that further aggravates underlying inflammatory reactions. Similar findings were reported by Suda et al. ${ }^{32}$ Moreover, the high expression of IgE and histamine in the atopic group could be associated with the pathological expression of $\mathrm{T}_{\mathrm{H} 2}$ cytokines. $\mathrm{T}_{\mathrm{H} 2}$ cytokines facilitate class switching of immunoglobulin $\mathrm{M}$ into IgE, and subsequently induce the degranulation of mast cells and basophils to release histamine locally and systemically. ${ }^{31,32}$ Similar to other mediators, the VGR expressed elevated levels of the $\mathrm{T}_{\mathrm{H} 2}$ cytokines, whereas the DermAid $0.5 \%$ cream significantly reduced their pathological expression. A further reduction in $\mathrm{T}_{\mathrm{H} 2}$ cytokines was observed in mice treated with the NP-based formulations, particularly QV-HC-CS-NPs. This finding was more prominent in skin, as shown in Figure $7 \mathrm{~A}-\mathrm{F}$.

\section{Proinflammatory cytokines}

Proinflammatory cytokines, including TNF- $\alpha$ and IL-6, were also investigated in the present study (Figure 8A-D). Similar to the other cytokines evaluated, atopic mice expressed the highest level of TNF- $\alpha$ in serum $(195 \pm 11 \mathrm{pg} / \mathrm{mL})$ and skin (174 $\pm 9 \mathrm{pg} / \mathrm{mL}, P<0.005$, one-way ANOVA). The baseline expression level was extremely low in serum $(18 \pm 5 \mathrm{pg} / \mathrm{mL})$, and was not detected in the skin homogenates. In addition, the concentration of IL-6 was elevated in atopic mice that did not receive treatment or were treated with vehicle creams, as shown in Figure 8B and D. IL-6 is associated with cell and membrane destruction at the site of injury, and thus is identified as a chemical signal for the infiltration of other anti-inflammatory cells. High expression of TNF- $\alpha$ and IL-6 could be associated with a high number of infiltrated macrophages and basophils into the dermis. Moreover, the pleiotropic nature of IFN- $\gamma$ might also contribute to the proliferation and differentiation of infiltrating macrophages via macrophage-stimulating factors, which tend to aggravate AD-like skin lesions. As expected, DermAid 0.5\% and NPbased formulations significantly reduced TNF- $\alpha$ and IL-6 levels ( $P<0.005$, one-way ANOVA). These findings were more prominent in the NP-based formulations, particularly in the skin (Figure 8A and D). Therefore, these findings suggest that the NP-based formulations may be a more promising therapeutic to inhibit the pathological enhancement of various proinflammatory cytokines in AD.
A

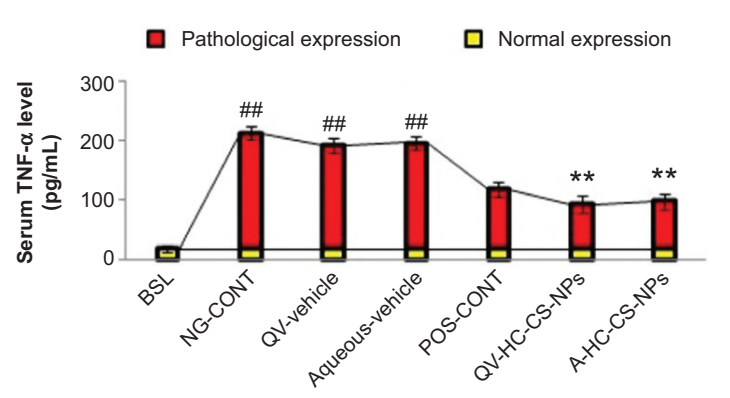

B

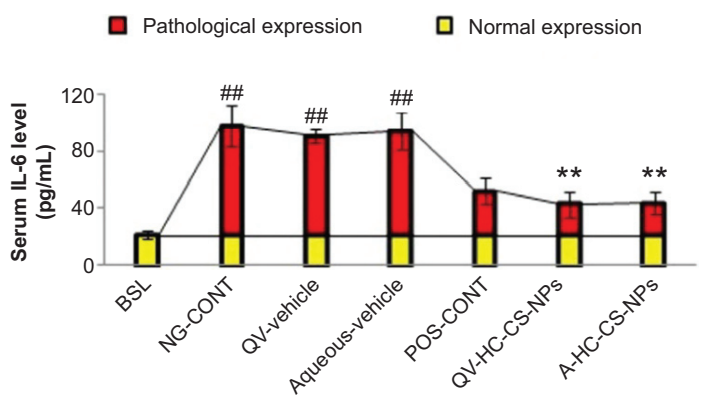

C

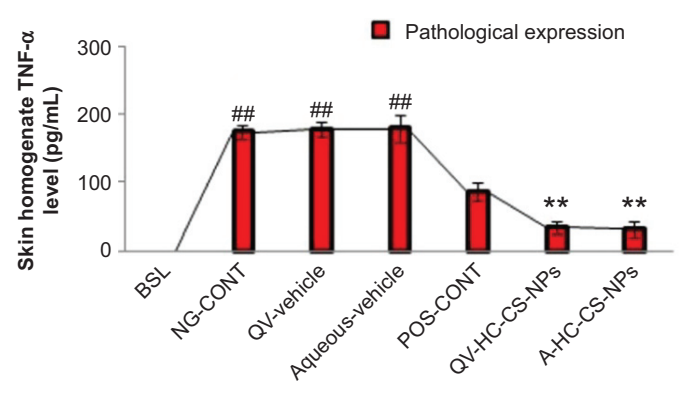

D

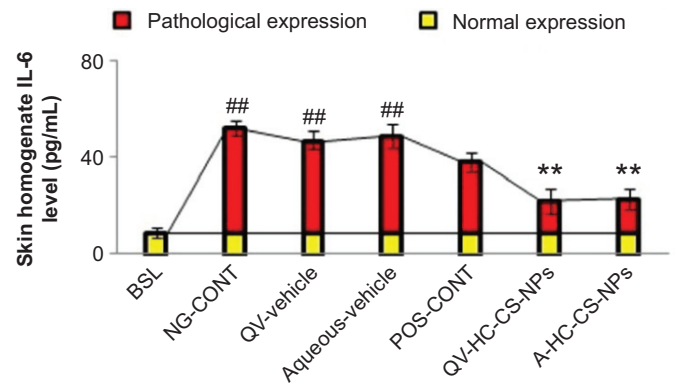

Figure 8 Immunomodulatory efficacy of NPs-based formulations.

Notes: Effect of HC-loaded CS-NP-based formulations on the expression of TNF- $\alpha$ and IL-6 in serum (A and $\mathbf{B})$ and skin tissue homogenates (C and $\mathbf{D})$ of AD-induced $\mathrm{NC} / \mathrm{Nga}$ mice compared to other groups treated. The yellow part of the bars represent normal expression, and the red part represents pathological expression of the AD-mediators. Data are presented as mean \pm standard deviation of triplicate experiments. ${ }^{\# P}<0.005$ baseline versus atopic mice/vehicle groups; ${ }^{* * P}<0.005 \mathrm{NP}$-based formulations versus atopic/vehicle groups.

Abbreviations: A, aqueous-based; AD, atopic dermatitis; BSL, baseline; CS, chitosan; HC, hydrocortisone; IL, interleukin; NG-CONT, negative control; NP, nanoparticle; POS-CONT, positive control; QV-, QV-cream; TNF- $\alpha$, tumor necrosis factor- $\alpha$. 


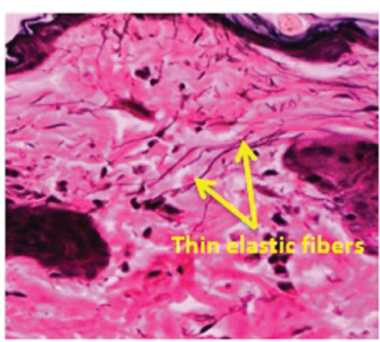

Normal/baseline mice

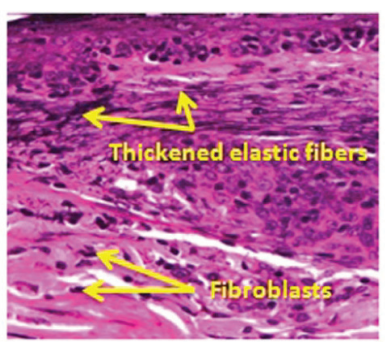

Atopic mice

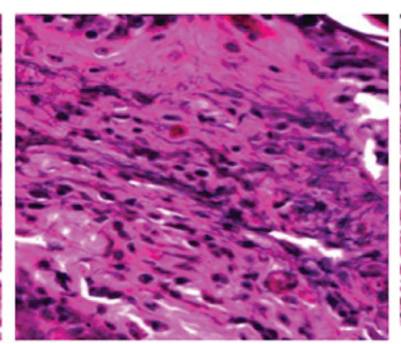

QV-vehicle treated mice

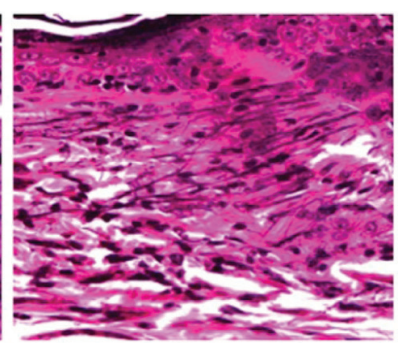

Aqueous-vehicle treated mice

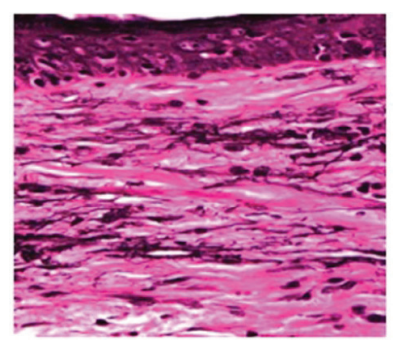

Positive control mice

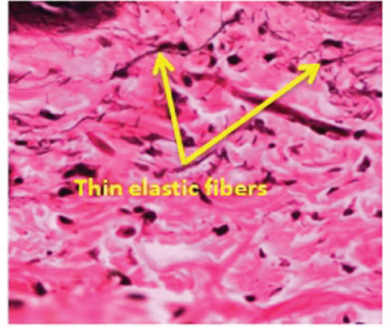

QV-HC-CS-NPs

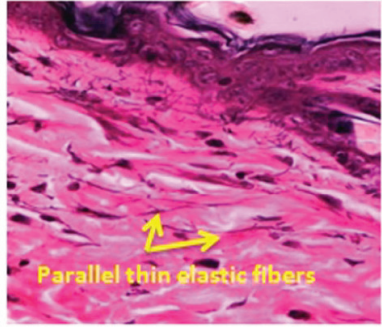

A-HC-CS-NPs

Figure 9 Histological photomicrographs of AD-like skin lesions of NC/Nga mice treated with NP-based formulations compared to baseline mice and other treated groups. Notes: The wavy fibers, which were stained black with VVG, represent elastic fibers. Photomicrographs were imaged under 400x magnification.

Abbreviations: A, aqueous-based; AD, atopic dermatitis; CS, chitosan; HC, hydrocortisone; NP, nanoparticle; QV-, QV-cream; VVG, Verhoeff-Van Gieson staining.

\section{Histological observation in AD-like skin lesions}

The photomicrographs of the histological features in all $\mathrm{NC} / \mathrm{Nga}$ mice are presented in Figure 9. Untreated atopic mice displayed dense and thickened elastic fibers in the papillary and reticular layers of the dermis. This condition would normally reduce skin elasticity and resilience, because elastic fibers are a key element for skin elasticity and any pathological stress may lead to skin fibrosis. A high number of infiltrated fibroblasts were also observed in the dermis of atopic mice, due to the underlying $\mathrm{AD}$ pathogenesis. The photomicrographs of vehicle mice also displayed thickening of the elastic tissues and fibroblast infiltration, although the density of the elastic fibers was not as thick as observed in the atopic mice. Despite a similar thickness in elastic fibers, the POS-CONT mice exhibited a reduction in infiltrated fibroblasts. Based on these findings, the commercial DermAid $0.5 \%$ formulation could cause a reduction in skin elasticity and resilience. In contrast, the NP-based formulations diminished infiltrating fibrocytes, which play a key role in tissue remodeling and skin fibrosis, and inhibited fibrogenesis and the thickening of elastic connective tissues. In addition, the elastic fibers in the mice treated with NP-based formulations displayed similar histological features, such as long and thin fibers arranged in parallel to the epidermis, as was the case with the baseline mice (Figure 9). These data further support the potential of CS-NPs in maintaining the integrity of the skin.

\section{Conclusion}

The objective of this study was to develop topical formulations of CS-NPs for the local delivery of HC, and to explore its clinical and immunological potential in managing AD-like skin lesions using an NC/Nga mouse model. Microscopic examination clearly demonstrated the therapeutic effectiveness of NP-based formulations in reducing the progression and severity of DNFB-induced AD-like skin lesions. The effectiveness of the NP-based topical formulations is expected, due to the interruption of a series of immunopathological events, including the production and release of IgE, histamine, $\mathrm{PGE}_{2}$, VEGF- $\alpha$, and other AD-associated inflammatory mediators. The promising reduction in the pathological features of $\mathrm{AD}$, including in the anatomical infrastructure of skin, fibroblast infiltration, and thickness of elastic fibers, supports the clinical potential of NP-based formulations as an alternative therapeutic approach in the management of $\mathrm{AD}$.

\section{Acknowledgments}

The authors gratefully acknowledge the Ministry of Higher Education, Malaysia and the Universiti Kebangsaan Malaysia (UKM) for supporting and funding this research project. The current research was funded by UKM Arus Perdana grant (AP-2013-002).

\section{Disclosure}

The authors report no conflicts of interest in this work. 


\section{References}

1. Alomar A, Berth-Jones J, Bos JD, et al. The role of topical calcineurin inhibitors in atopic dermatitis. Br J Dermatol. 2004;151 Suppl 70: $3-27$.

2. Şenyiğit T, Padula C, Ozer O, Santi P. Different approaches for improving skin accumulation of topical corticosteroids. Int J Pharm. 2009;380(1-2):155-160.

3. Schoepe S, Schäcke H, May E, Asadullah K. Glucocorticoid therapyinduced skin atrophy. Exp Dermatol. 2006;15(6):406-420.

4. Zöller NN, Kippenberger S, Thaçi D, et al. Evaluation of beneficial and adverse effects of glucocorticoids on a newly developed full-thickness skin model. Toxicol In Vitro. 2008;22(3):747-759.

5. Kaplun-Frischoff Y, Touitou E. Testosterone skin permeation enhancement by menthol through formation of eutectic with drug and interaction with skin lipids. J Pharm Sci. 1997;86(12):1394-1399.

6. Sammeta SM, Vaka SR, Murthy SN. Transcutaneous electroporation mediated delivery of doxepin-HPCD complex: a sustained release approach for treatment of postherpetic neuralgia. J Control Release. 2010;142(3):361-367.

7. Prausnitz M. Microneedles for transdermal drug delivery. Adv Drug Deliv Rev. 2004;56(5):581-587.

8. Heuschkel S, Goebel A, Neubert RH. Microemulsions - modern colloidal carrier for dermal and transdermal drug delivery. J Pharm Sci. 2008;97(2):603-631.

9. Trotta M, Peira E, Debernardi F, Gallarate M. Elastic liposomes for skin delivery of dipotassium glycyrrhizinate. Int J Pharm. 2002; 241(2):319-327.

10. Fang YP, Huang YB, Wu PC, Tsai YH. Topical delivery of 5 -aminolevulinic acid-encapsulated ethosomes in a hyperproliferative skin animal model using the CLSM technique to evaluate the penetration behaviour. Eur J Pharm Biopharm. 2009;73(3):391-398.

11. Jenning V, Gysler A, Schäfer-Korting M, Gohla S. Vitamin A loaded solid lipid nanoparticles for topical use: occlusive properties and drug targeting to the upper skin. Eur J Pharm Biopharm. 2000;49(3):211-218.

12. Wu H, Ramachandran C, Weiner ND, Roessler BJ. Topical transport of hydrophilic compounds using water-in-oil nanoemulsions. Int J Pharm. 2001;220(1-2):63-75.

13. Lademann J, Richter H, Teichmann A, et al. Nanoparticles - an efficient carrier for drug delivery into the hair follicles. Eur J Pharm Biopharm. 2007;66(2):159-164.

14. Biruss B, Valenta C. Skin permeation of different steroid hormones from polymeric coated liposomal formulations. Eur J Pharm Biopharm. 2006;62(2):210-219.

15. Kuchler S, Radowski MR, Blaschke T, et al. Nanoparticles for skin penetration enhancement - a comparison of a dendritic core-multishellnanotransporter and solid lipid nanoparticles. Eur J Pharm Biopharm. 2009;71(2):243-250.

16. Wu X, Price GJ, Guy RH. Disposition of nanoparticles and an associated lipophilic permeant following topical application to the skin. Mol Pharm. 2009;6(5):1441-1448.
17. Hussain Z, Katas H, Mohd Amin MC, Kumolosasi E, Buang F, Sahudin S. Self assembled polymeric nanoparticles for percutaneous co-delivery of hydrocortisone/hydroxytyrosol: an ex vivo and in vivo study using an NC/Nga mouse model. Int J Pharm. 2013;444(1-2):109-119.

18. Grewe M, Bruijnzeel-Koomen CA, Schöpf E, et al. A role for Th1 and Th2 cells in the immunopathogenesis of atopic dermatitis. Immunol Today. 1998;19(8):359-361.

19. Leung DY. Atopic dermatitis: new insights and opportunities for therapeutic intervention. J Allergy Clin Immunol. 2000;105(5):860-876.

20. Galli SJ, Nakae S, Tsai M. Mast cells in the development of adaptive immune responses. Nat Immunol. 2005;6(2):135-142.

21. Zhang $\mathrm{Y}$, Matsuo $\mathrm{H}$, Morita E. Increased production of vascular endothelial growth factor in the lesions of atopic dermatitis. Arch Dermatol Res. 2006;297(9):425-429.

22. Jung MK, Hur DY, Song SB, et al. Tannic acid and quercetin display a therapeutic effect in atopic dermatitis via suppression of angiogenesis and TARC expression in $\mathrm{Nc} / \mathrm{Nga}$ mice. J Invest Dermatol. 2010;130(5):1459-1463.

23. Kang MJ, Eum JY, Park SH, et al. Pep-1 peptide-conjugated elastic liposomal formulation of taxifolin glycoside for the treatment of atopic dermatitis in NC/Nga mice. Int J Pharm. 2010;402(1-2):198-204.

24. Lee HS, Kim SK, Han JB, et al. Inhibitory effects of Rumex japonicus Houtt. on the development of atopic dermatitis-like skin lesions in $\mathrm{NC} /$ Nga mice. Br J Dermatol. 2006;155(1):33-38.

25. Papadimitriou S, Bikiaris D, Avgoustakis K. Chitosan nanoparticles loaded with dorzolamide and pramipexole. Carbohyd Polym. 2008;73(1):44-54.

26. El-Hefian EA, Elgannoudi ES, Mainal A, Yahaya AH. Characterization of chitosan in acetic acid: Rheological and thermal studies. Turk J Chem. 2010;34:47-56.

27. Clausen AE, Bernkop-Schnürch A. Thiolated carboxymethylcellulose: in vitro evaluation of its permeation enhancing effect on peptide drugs. Eur J Pharm Biopharm. 2001;51(1):25-32.

28. Matsuda H, Watanabe N, Geba GP, et al. Development of atopic dermatitis-like skin lesion with IgE hyperproduction in NC/Nga mice. Int Immunol. 1997;9(3):461-466.

29. Galli SJ, Tsai M, Piliponsky AM. The development of allergic inflammation. Nature. 2008;454(7203):445-454.

30. Hussain Z, Katas H, Amin MCIM, Kumolosasi E, Sahudin S. Antidermatitic perspective of hydrocortisone as chitosan nanocarriers: an ex vivo and in vivo assessment using an NC/Nga mouse model. J Pharm Sci. 2013;102(3):1063-1075.

31. Tomimori Y, Tanaka Y, Goto M, Fukuda Y. Repeated topical challenge with chemical antigen elicits sustained dermatitis in $\mathrm{NC}$ / Nga mice in specific-pathogen-free condition. J Invest Dermatol. 2005;124(1):119-124.

32. Suda N, Yu X, Kubo C. Dehydroepiandrosterone attenuates the spontaneous elevation of serum IgE level in $\mathrm{NC} / \mathrm{Nga}$ mice. Immunol Lett. 2001;79(3):177-179.
International Journal of Nanomedicine

\section{Publish your work in this journal}

The International Journal of Nanomedicine is an international, peerreviewed journal focusing on the application of nanotechnology in diagnostics, therapeutics, and drug delivery systems throughout the biomedical field. This journal is indexed on PubMed Central, MedLine, CAS, SciSearch ${ }^{\circledR}$, Current Contents ${ }^{\circledR} /$ Clinical Medicine,
Dovepress

Journal Citation Reports/Science Edition, EMBase, Scopus and the Elsevier Bibliographic databases. The manuscript management system is completely online and includes a very quick and fair peer-review system, which is all easy to use. Visit http://www.dovepress.com/ testimonials.php to read real quotes from published authors. 